\title{
SO-CALLED SYRIAN ALKANET, MACROTOMI'A CEPHALOTES, D. C.*
}

BY CLARE OLIN EWING AND JOSEPH F. CLEVENT.FER.

A sample of "Alkanet," recently submitted for our examination, proved to be, not the root of true Alkanet (Alkanna tinctoria Tausch), but that of so-called Syrian Alkanet (Macrotomia cephalotes, D. C.). Both the plants named belong to the Boraginaceae, and are indigenous to Asia Minor and southeastern Europe.

Previous investigators have observed alkannin-like tinctorial principles in other members of the Borage family. Vogtherr ${ }^{1}$ has noted several foreign pigment-bearing species of Boraginaceae, and has discussed Macrotomia cephalotes in some detail. His description of "Syrian Alkanet" is accurate, although his accompanying sketch shows a root somewhat larger than any which we have observed. From Macrotomia he extracted 9.13 percent of a crude coloring matter which "seemed to be identical with that of Alkanet." His paper does not indicate the solvents or methods used in extraction. Coloring matters have also been noted by Norton ${ }^{2}$ in a number of American Boraginaceae. While this investigator. made no analysis of the tinctorial principles of his material, by testing with resins and oils he obtained an alkannin-like reaction from the leaves and roots of Plagiobothrys, and suggested the possible utilization of some of these plants.

The submitted sample (Fig. I) was easily distinguishable from true alkanet root. It was very much larger in size; it occurs in pieces from 20 to $40 \mathrm{~cm}$. long and 2 to $5 \mathrm{~cm}$. thick, whereas alkanet is about $I$ to $1.5 \mathrm{~cm}$. in diameter and is usually ro to $15 \mathrm{~cm}$. long, although it sometimes occurs in pieces up to $25 \mathrm{~cm}$. in length. The sample also was many headed, in contradistinction to the one or few heads of alkanet. It was black-violet in color and somewhat metallic in appearance, whereas alkanet is of a dull maroon color. Alkanet is only slightly twisted, while the "Syrian Alkanet" had a distinctly spiral twist, resembling a twist of tobacco. Vogtherr's figures shows a specimen with a much shorter spiral than any which we have observed. A section of alkanet shows that the wood is centrally placed and is surrounded by a tissue of loose, almost spongy texture. In the sample of "Syrian Alkanet" the wood, which was straw-yellow in color, was laterally placed and was accompanied

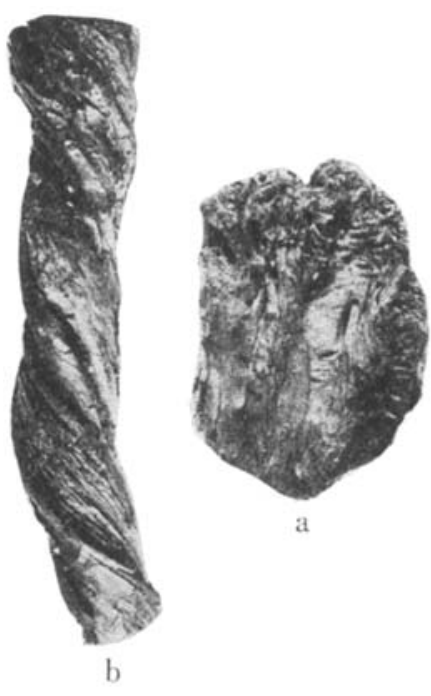

Fig. 1.

Root of Macrotomia cephalotes. a.- Top showing heads. b.- Portion of main body. by a layered coffee-brown-gray tissue on the inside, and a blackish violet color on the outside.

* Contribution from Pharmacognosy Laboratory, Bureau of Chemistry, Department of Agriculture, Washington, D. C.

1 Vogtherr, "Úber Alkanna und ihre Verwandten," Pharm. Centralh., 37, 148-52 (1896).

"Norton, "The Coloring Matter Found in Some Boraginaceae," Amer. Journ. Pharm., $70,346-8$ (1898). 
Samples of both products were ground to a No. 20 powder and the coloring matter completely extracte 1 from ro-gramme samples with chloroform in a Soxhlet extractor, the extractc evaporated on the steam bath and dried at $100^{\circ} \mathrm{C}$. It amounted, the case of true alkanet to slightly over 5 percent; in the "Syrian Alkanet" it amounted to about 9 percent. 'The colored extract, crude alkannin from alkanet is generally reported as varying from about 4 to 6 percent, depending somewhat on the solvent used. As mentioned above, Vogtherr reports 9.I3 percent of extract for a sample of "Syrian Alkanet," but does not indicate the nature of the solvent.

Both extracts were dark brownish red, metallic glistening masses, the Syrian Alkanet being a trifle darker. They softened under $100^{\circ} \mathrm{C}$. (steam bath) without having a definite melting point. This was due, no doubt, to the wax which, according to Liebermann and Römer ${ }^{3}$ is, after alkannin, the principal constituent of the extract. They isolated this wax from commercial crude alkannin and found it to be hydrocarbon melting at $75^{\circ} \mathrm{C}$.

The alcoholic solution of both extracts varied from cerise to a dark red, depending upon the concentration. The colors apparently were very nearly identical, that from Syrian alkanet being perhaps of a more purplish shade. Colorimetric comparison of solutions of the two extracts of similar concentration showed that the proportions of coloring matter in both were approximately the same.

Gawalowski $\mathrm{i}^{4}$ has stated that the coloring matter of alkanet is not a single chemical individual, but contains two coloring constituents. 'The first, which is extracted with petroleum ether, he called anchusic acid (anchusa red), and ascribed to it the probable formula $\mathrm{C}_{30} \mathrm{H}_{30} \mathrm{O}_{7}$; the second, which he extracted with ether and alcohol, he called alcannic acid (alkanna red) and ascribed to it the probable formula $\mathrm{C}_{15} \mathrm{H}_{14} \mathrm{O}_{4}$ (or $\mathrm{C}_{30} \mathrm{H}_{28} \mathrm{O}_{8}$ ). In view of this statement, fractional extraction was made of both products, with the following results:

\begin{tabular}{|c|c|c|}
\hline & Alkanet. & "Syrian Alkanet." \\
\hline Petroleum ether extract. & 3.36 percent & 4.69 percent \\
\hline$\ldots \ldots \ldots \ldots \ldots \ldots$ & 1.22 percent & 3.64 percent \\
\hline Chloroform...... & $\begin{array}{l}0.61 \text { percent } \\
\text { trace }\end{array}$ & $\begin{array}{l}0.66 \text { percent } \\
\text { trace }\end{array}$ \\
\hline & 5.19 percent & 8.99 percent \\
\hline
\end{tabular}

Both of the petroleum ether extracts were bright red in color, dark red in thicker layers. The ethereal extracts were of a purplish black color and were insoluble in petroleum ether. Both had an odor of acetic and butyric acids, similar to that which we have noted in a commercial specimen of crude alkannin. The chloroform extracts were also of a purplish black color and were insoluble in ether and petroleum ether. The alcoholic solutions of the petroleum ether extracts were of an intense bright red color. The alcoholic solutions of the ether and chloroform extracts were of a less intense purplish red color than those of

s "Uber Alkannin," Ber., 20, 243 I (1887).

'Gawalowski, A., "Die Pigmente der 'Radix Anchusa tinctoria' in ihrer Bedeutung für die alkalimetrische und acidimetrische Analyse," Zeit. anal. Chem., 42, 108-9 (1913). 
petroleum ether, the difference in intensity and shade being more pronounced in the higher dilutions. The large amount of the ether and chloroform extracts in the Syrian Alkanet explains the purplish tint of the preliminary chloroform extract noted above. The color tests, which are tabulated below, show that the material extracted by petroleum ether differed chemically from those extracted by ether and by chloroform. Although the two latter were obtained separately, their reactions with the various reagents used were similar and they are therefore not listed separately.

Color Reactions of Alikanet and Syrian Al,kanet.

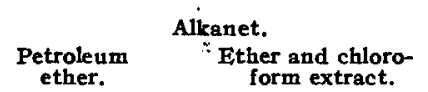

Basic lead acetate.. Deep purple color Bluish gray color Dee and precipitate and turbidity

Uranium acetate. Bluish gray color Dirty green color Ammonium h y - Indigo-blue color; Violet color droxide........ purplish shade

P otassium hy - Indigo-blue color droxide.......... less purplish
Light blue color; Indigo-blue color
faint suggestion of green

Stannous chloride. Cherry-red color; Paler color than Cherry-red color; Paler color than yellow after addi- P. E. extract tion of $\mathrm{HCl}$ yellow after addi- P. E. extract tion of $\mathrm{HCl}$

Ferric chloride..... Dark violet color Dirty greenish Dark violet color Dirty greenish and turbidity brown color and turbidity brown color

Mercuric chloride.. Bright cherry-red Pink color Bright cherry-red Pink color color; purplish red precipitate color; purplish red precipitate

In addition to the above reactions, the color of all three extracts of both the alkanet and the "Syrian Alkanet" was destroyed when a few drops of a saturated solution of bromine water were added to a dilute alcoholic solution; the color was restored by the subsequent addition of several drops of 3 percent hydrazine sulphate solution. This reaction is considered by Mathewson ${ }^{5}$ to be quite specific for alkanet.

An extract of "Syrian Alkanet," prepared with 95 percent alcohol, diluted with water to 50 percent concentration of alcohol, gave very satisfactory results in this laboratory and in the Microbiological Laboratory of this Bureau in the staining for microscopic observation of sections containing fats (soy beans, castor beans, yellow mustard seed, etc.) and resins (podyphyllum rhizome and white bryony root).

The specimen of "Syrian Alkanet" was clean and free from dirt and other foreign materials. The genuine alkanet, while apparently quite clean, upon close inspection showed the presence of minute particles of sand, which adhered very tenaciously to it. We have observed this condition in a number of other commercial specimens of alkanet. Ash and ash-insoluble determinations on two-gramme portions of the No. 20 powder gave the following results:

s Mathewson, W. E., "Separation and Identification of Food-Coloring Substances," Department of Agriculture, Buil. 54, $44^{8}$ (1917). 


\begin{tabular}{|c|c|c|}
\hline & Alkanet. & "Syrian Alkanet." \\
\hline $\begin{array}{l}\text { Total ash......... } \\
\text { Acid-insoluble ash }\end{array}$ & $\begin{array}{r}17.0 \text { percent } \\
8.0 \text { percent }\end{array}$ & I I . 7 percent \\
\hline
\end{tabular}

The ash in both cases was high in carbonates

From the above data it may be seen that the coloring extracts from both plants consist of at least two chemical individuals and that both extracts are very similar in nature. In view of the fact that in Syrian Alkanet the coloring extract was present in much larger amount than in the true alkanet, and possessed equivalent tinctorial strength, it would appear to be a valuable substitute for the latter.

\section{THE ESTIMATION OF ALCOHOL.*}

BY C. R. HARER.

While the estimation of alcohol in pharmaceutical preparations is not very complicated, it, nevertheless, presents many difficulties and affords opportunities for experiment and research.

Frothing, in numerous cases, is readily controlled by tannic acid; while in particular instances sulphuric or phosphoric acid, as advised by some writers may be preferable, I find tannic acid more generally practical, although the variation of its action with different drugs has not been determined. After the addition of tannic acid to fluidextracts of gelsemium, helonias and several other drugs, they must be heated very rapidly to boiling to control the frothing. The addition of tannic acid to fluidextracts of black haw, mango bark and several others increases the frothing instead of retarding it. The addition of tannic acid to preparations of cinchona produces an uncontrollable frothing when heat ed, while if heated slowly without tannic acid, the liquid will froth at first, but the foam will soon subside and regular boiling take place; the initial frothing may be almost instantly eliminated if the liquid is heated rapidly in such a way that the flame is thrown on the upper part of the distilling flask for a few seconds, when the liquid starts to boil.

The estimation of alcohol in fluidextract of sarsaparilla presents greater difficulties than many other preparations, and the following experiments were undertaken for the purpose of finding a convenient and rapid method for its determination: Mechanical methods (paraffin, fixed oils, etc.) to control the frothing were tried, but without success. Baryta water was then used to precipitate the saponins and resins, but this gave no satisfactory results. Several experiments were made by adding a suspension of aluminum hydroxide to the fluidextracts also by adding an aluminum salt to the fluidextract and subsequently precipitating the hydroxide with a caustic alkali. These experiments were failures. Next an addition of the official solution of lead subacetate was tried, but I found that a direct distillation of fluidextract of sarsaparilla with lead subacetate solution was impracticable because frothing was unavoidable and it was impossible to separate the aqueous alcoholic liquid quantitatively from the voluminous gelatinous precipitate by fil-

* Read before Scientific Section, A. Ph. A., Indianapolis meeting, 1917. 